\title{
LA CASA-PALACIO DE ANGLONA
}

Antonio Bonet Correa, Académico de Número de la Real Academia de Bellas Artes de San Fernando

Raros son los ejemplos que se conservan de la arquitectura civil madrileña del Antiguo Régimen. En primer lugar hay que considerar que la Villa, convertida en Corte desde 1561 no tuvo gran suerte en lo que se refiere a la monumentalidad y magnificencia de las mansiones señoriales. Aparte de algunos pocos ejemplos como el palacio de D. Alonso Gutiérrez, Contador de los Reyes Católicos y Tesorero de Carlos V, convertido muy pronto en Monasterio de las Descalzas Reales o de la muy reconstruida modernamente Casa del sobrino de Cisneros o la todavia aún más transformada Casa de las Siete Chimeneas, son pocos los testimonios que se conservan de la arquitectura civil del siglo XVI.

Desaparecidos el Alcázar Real y la mayor parte del Palacio del Buen Retiro, el Palacio del Duque de Lema y Casas como la de Oñate -a la que todavia se pudo fotografiar- sólo queda como ejemplo de residencia noble del siglo XVII el $\mathrm{Pa}$ lacio de Uceda hoy Capitanía General y Palacio de los Consejos. Bien es cierto que los nobles españoles del Siglo de Oro en Madrid habitaron en vastos e inóspitos caserones, incluso a veces destartalados, impropios de su rango. Poseedores en sus ciudades de origen de palacios del siglo XV o de la primera mitad del siglo XVI cuando tuvieron que trasladarse a la Corte se instalaron en casas como si se tratase de casas improvisadas o provisionales. En su solar de origen tenian el palacio del que se sentian orgullosos, en la Corte no estaban más que aposentados temporalmente, con muebles y obras de arte que alhajaban las estancias. Las casas era meros contenedores a manera de tiendas de campaña o habitación de posada y tránsito momentáneo.

De sobra es conocido como el Cardenal Barberini se asombra de la poca importancia que tenian las mansiones de los Grandes de España. Otros testimonios, como el de la francesa condesa de Aulnoy lo confirman. El lujo de las familias estaba de cara a la calle: en las carrozas o en las fiestas, en las que la casa se enmascaraba con fachadas de arquitectura efímera, muy costosa de momento pero no tanto como la definitiva y nunca emprendida.
Fue el advenimiento de los Borbones lo que cambió el panorama arquitectónico de la casa noble madrileña. José Benito de Churriguera construyó una espléndida mansión para el Ministro D. José de Goyeneche, transformada más tarde por Diego de Villanueva para sede de la Academia de Nobles Artes de San Fernando.

Pedro de Ribera edificó también vistosas mansiones todavia algunas en uso, aunque transformadas en casas o pisos o sede de una institución mercantil, con sus ricas y decoradas portadas, estas casas-palacio comenzaron a dar prestancia a la ciudad-convento que era Madrid, pero fue ya en la segunda mitad del siglo XVIII cuando se inició un nuevo tipo de casa noble, exenta en sus cuatro fachadas, con jardines y perspectivas monumentales. Los palacios de Liria, hoy casa de los Alba, y el Palacio de Bellavista, para los Alba, hoy Cuartel General del Ejército, son ejemplos singulares de la mutación sufrida por una clase que, en la cúspide del poder social, supo ponerse al nivel de la Europa culta anterior a la Revolución Francesa.

La casa de Anglona es un ejemplo singular de la casa noble española en todas sus fases y tipología. Situada en el corazón del viejo Madrid, aledaña a la iglesia más vieja de la Villa y de la típica Plaza de la Paja o del Marqués de Comillas, en donde tenian su casa los Vargas es a la vez una casona y un palacio, fruto de los arreglos y ensanches de una vetusta mansión de la época de los Austria que, en tiempo de los Borbones, se transforma en casa-palacio de gran porte, tanto al exterior como en su rico interior, reestructurado y decorado de acuerdo con la última y más refinada moda neoclásica.

Su interés es enorme por el sincretismo de su conjunto. De señalar son en la fachada que da a la Cuesta de la calle Segovia sus covachuelas y puertas para tiendas y almacenes ya de la casa o de alquiler. También su doble portada, separando la casa de respeto de la doméstica.

En el interior, el interés del palacio se acrecienta en la parte destinada a residencia del segundo 


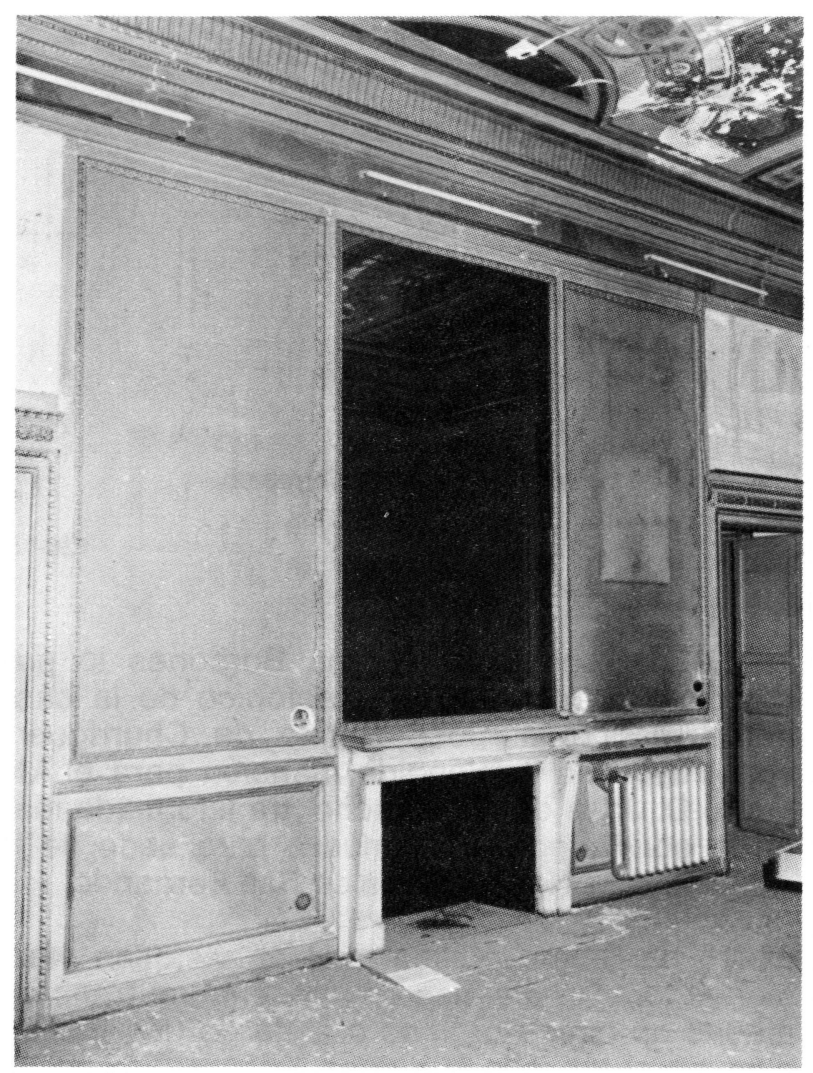

hijo de la duquesa de Benavente, D. Pedro de Alcántara Tellez-Girón y Pimentel, Príncipe de Anglona y marqués de Javalquinto. Para la boda de su hermano primogénito se arreglaron las estancias de la planta noble que mira a la calle de Segovia y al jardín. Alli se pusieron los grandes saIones con pinturas decorativas de techos y se diseñó todo un conjunto interior que comprende un ámbito íntimo -habitación nupcial, vestidor, tocador y baño- de refinado gusto entre pompeyano y francés del Imperio. Es de señalar como este conjunto, coquetamente dispuesto, constituye un mundo de cofre cerrado, a la vez lúdico e íntimo. Se trata de un templo del amor, de una alcoba para una época prerromántica en la que en determinados medios sociales se cuidaban los detalles hasta el último extremo.

\section{Aspecto unitario de la decoración interior}

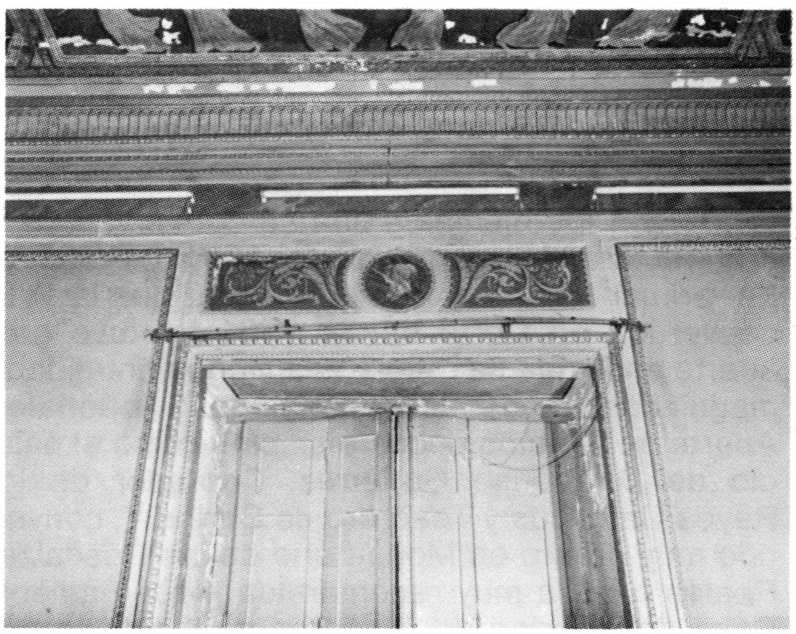

Las ventanas sobre el jardin, en una alcoba situada al Poniente, que recoge en sus espejos los últimos resplandores del día se convierte, así, según va llegando la noche y envolviéndose en la penumbra, en un camarín secreto de delicias.

La casa-palacio de Anglona, pintada al exterior con color rosa salmón -muy de la época se vuelve con este interior blanco, azul y gris- un discreto gineceo para un joven aristócrata de la estirpe más culta e intelectual de la época.

Los duques de Benavente no podian ofrecer un marco más adecuado para la boda de su primogénito, continuador de una casa que, entre las españolas, se distinguió por su acendrada cultura y airosa manera de vivir. 